\title{
Lens epithelial cell proliferation, migration, and metaplasia following capsulorhexis
}

\author{
Lisa Saxby, Emanuel Rosen, Mike Boulton
}

\begin{abstract}
Aim-To study the behaviour of residual lens epithelial cells after capsulorhexis and expression of material from the isolated lens.

Methods-Human and bovine lens capsules were isolated, sterile non-toxic silicone rings inserted, and the preparations placed in organ culture for up to 12 weeks. Cell coverage of the posterior lens capsule was recorded and the capsules were examined, both pre- and post-coverage, for (a) proliferative activity and (b) cytoskeletal components.

Results-After a lag period outgrowth was observed across the posterior capsule. The rate of cell coverage was dependent upon both species and the presence or absence of serum. The proliferative activity of the cells was greatest at or near the leading edge and decreased once covered. Wrinkles became visible in the posterior capsule during the late stages of precoverage and increased in both number and complexity. All cells on both the human and bovine posterior capsules contained F-actin and vimentin and the majority were immunolabelled for $\alpha$-smooth muscle actin ( $\alpha$-SMA).

Conclusions-This model exhibits many of the in vivo characteristics of the lens capsule after extracapsular surgery and may prove useful in further elucidating the cellular mechanisms of posterior capsule opacification.

(Br F Ophthalmol 1998;82:945-952)
\end{abstract}

Extracapsular cataract extraction (ECCE), often using phacoemulsification is now established as the optimal surgical technique to treat most cataracts. ${ }^{1}$ It not only allows the insertion of a posterior chamber intraocular lens, but also maintains an intact posterior capsule therefore reducing the incidence of a number of postoperative complications associated with intracapsular cataract extraction..$^{2-4}$ Posterior capsule opacification (PCO), a major complication of ECCE, occurs in up to $50 \%$ of patients between 2 months and 5 years after the initial surgery. ${ }^{5}$ Opacification occurs as a result of the formation of fibrotic membranes and/or Elschnig's pearls on the posterior capsule. ${ }^{5}$ Fibrocellular membranes result from excessive proliferation and migration of residual lens epithelial cells to form a layer, or layers, of cells over the anterior surface of the posterior capsule. The cells in this membrane are believed to have undergone phenotypic change to a fibroblast-like cell whose contrac- tile properties can cause extensive wrinkling of the posterior capsule and which, in addition, secretes extracellular matrix. ${ }^{7}$ Elschnig's pearls represent the aberrant attempts of lens epithelial cells to differentiate into lens fibres. ${ }^{9}{ }^{10}$ Vision is compromised when opacification from these events occurs in the visual axis.

Several approaches have been used to provide further insight into the cellular and molecular mechanisms involved in the formation of PCO. These range from simple cell culture techniques to in vivo models. ${ }^{11-16}$ While these techniques have provided a wealth of information on the cell biology of lens epithelial cells, our understanding is still limited regarding PCO. Cell culture techniques are oversimplified with cells usually being grown in the absence of the posterior capsule, using serum containing medium which fails to mimic the aqueous, and often relying on non-human epithelial cells which usually have a higher proliferative activity. By contrast, animal models are complex, expensive, and the outcomes species dependent. A recent compromise is the model of Liu et $a l^{17}$ which utilises organ culture techniques to study the cellular events of PCO which, for human capsules, allow lens epithelial coverage to occur under serum free conditions. Using a different organ culture model we can substantiate the findings of Liu et al ${ }^{17}$ and Wormstone et $a l^{18}$ as well as documenting species variation and providing a detailed histological description of the different stages of capsule coverage.

\section{Materials and methods}

ISOLATION AND PREPARATION OF HUMAN LENS CAPSULES

Twenty four pairs of human eyes between 16 and 72 hours post mortem (donor age, 50-93; mean 72), which had been donated for research, were obtained from the Manchester Eye Bank. The cornea and a thin rim of sclera had previously been removed for storage and corneal transplantation. The isolation of the lens capsule was carried out under a dissecting microscope. Four cuts were made in the iris from the pupillary edge to the ciliary body and each section peeled back beyond the equator of the lens and then cut off. Part of the anterior lens capsule was then removed by performing an anterior capsulorhexis using trans-scleral illumination. The cortex and nucleus were expressed by hydrodissection with phosphate buffered saline (PBS) and any cortical remnants removed with a pair of forceps. Sterile $9.63 \times 1.78 \mathrm{~mm}$ (external diameter $\times$ height) non-toxic silicone rings (E-A-P International Ltd, Manchester) were inserted into the 
capsule through the capsulorhexis. Four regularly spaced notches $(1 \mathrm{~mm}$ wide $\times 1 \mathrm{~mm}$ deep) had previously been cut into each ring on the surfaces that were in contact with the capsule. The lens capsule preparation was then isolated by cutting the zonules as close to the capsule as possible. Each capsule was transferred to a 60 $\times 15 \mathrm{~mm}$ petri dish and immersed in Waymouth's MB 752/1/Ham's F12 (both from Gibco, Paisley) (1:1) (v/v) which contained either $20 \%$ fetal calf serum (FCS) or was serum free. The medium was further supplemented with $1 \% 100 \mathrm{X}$ non-essential amino acids (Gibco), $200 \mu \mathrm{g} / \mathrm{ml}$ kanamycin sulphate, $120 \mu \mathrm{g} / \mathrm{ml}$ benzylpenicillin, $290 \mu \mathrm{g} / \mathrm{ml}$ streptomycin sulphate, and $200 \mu \mathrm{g} / \mathrm{ml} \mathrm{L}$-glutamine (all from Sigma, Poole, unless otherwise stated). One capsule from each pair of eyes was cultured in serum containing media and the other in serum free media. All capsules were cultured in standard incubator conditions $\left(37^{\circ} \mathrm{C}, 5 \%\right.$ carbon dioxide $/ 95 \%$ air). Previous in vitro experiments using bovine lens epithelial cells had shown that the rings were neither toxic nor altered the proliferative activity of the cells (data not shown).

\section{ISOLATION AND PREPARATION OF BOVINE LENS} CAPSULES

A total of 56 bovine eyes (animals under 30 months) were obtained from the Manchester abattoir within 30 minutes of sacrifice and kept on ice until use (within 4 hours). Each eye was bisected posterior to the ora serrata and the posterior segment discarded. The lens was isolated by cutting the zonules as close to the lens equator as possible while ensuring no capsular damage, and carefully dissecting the remaining vitreous from the posterior capsule. The majority of the anterior lens capsule was then removed by performing a circular capsulorhexis (3-4 $\mathrm{mm}$ of residual anterior capsule near the equator was left behind) and the lens hydrodissected by rapidly injecting PBS between the capsule and the cortex. Digital pressure was applied on opposing sides of the lens at the equator and the cortex and nucleus ejected. Any cortical remnants were gently removed with a pair of forceps. Sterile $16.04 \times$ $1.78 \mathrm{~mm}$ non-toxic silicone rings were inserted into the bovine capsules through the capsulorhexis. Eight regularly spaced notches $(3 \mathrm{~mm}$ wide $\times 1 \mathrm{~mm}$ deep) had previously been cut into each ring on the surfaces that were in contact with the capsule (Fig 1A). Each capsule was transferred to a $60 \times 15 \mathrm{~mm}$ petri dish and immersed in the medium described above for the human capsules. Twenty eight bovine lens capsules were cultured in medium containing $20 \%$ FCS and 28 capsules were cultured in serum free medium.

COVERAGE OF THE CAPSULE

Capsules were observed every 24 hours using a Zeiss Axiovert 35 inverted, phase contrast, light microscope (Zeiss, Oberkochen, Germany). Cellular coverage of the posterior capsule was recorded at each time point using a $\times 2.5$ objective and a $10 \times 10$ eye piece graticule. In the case of the bovine capsules which did not fit into one field of view the graticule was used in conjunction with a subsidiary grid positioned on the microscope stage which helped to locate the specimen for measurement of different fields. The number of squares completely or half covered by cells was recorded on a chart and the percentage coverage calculated by relating this to the area available within the ring used. Once covered both bovine and human capsules were observed every day for the first 4 days post-coverage and every 4 days thereafter. Capsular changes were noted on the grid at each observation. The medium was changed every 2 days until the capsules were covered and every 4 days thereafter. Capsules were photographed at various time intervals.

\section{HISTOLOGY}

Lens capsules plus rings at varying stages of coverage and post-coverage were fixed in 10\% neutral buffered formalin (NBF) for at least 12 hours. Four cuts were made from the capsulorhexis edge to the equator of the capsule. These anterior capsular flaps were peeled back and the ring removed. The lens capsules were then embedded in paraffin wax and $7 \mu \mathrm{m}$ thick sections cut. Sections were dewaxed in xylene, rehydrated through a graded series of alcohols, and stained with haematoxylin and eosin. The sections were examined by standard light microscopy using an Olympus Vanox AHBS3 microscope (Olympus, London) and photographed.

\section{THYMIDINE AUTORADIOGRAPHY}

Six bovine capsules (three in serum containing medium and three in serum free) and three pairs of human capsules (one of each pair in serum and the other serum free) were assessed at approximately $50 \%$ coverage. Bovine and human capsules were also assessed at 2, 4, 6, 12 , weeks and 6 and 12 weeks post-coverage respectively. Capsules were washed with PBS and incubated for 6 hours in Waymouth's MB $752 / 1$ containing $20 \%$ FCS or serum free, non-essential amino acids, antibiotics, glutamine and methyl- ${ }^{3} \mathrm{H}$ thymidine $(6 \mu \mathrm{Ci}$ per capsule) (DuPont, Stevenage). Following incubation, capsules were washed with $3 \times \mathrm{PBS}$ and fixed in $10 \% \mathrm{NBF}$ for a minimum of 12 hours. The ring was removed (as above) and the partially covered capsules attached to the base of a $60 \times 15 \mathrm{~mm}$ petri dish by drying at room temperature overnight. The cell nuclei were stained with propidium iodide $(15 \mu \mathrm{g} / \mathrm{ml})$ (Sigma). Post-coverage capsules were embedded in paraffin wax and then sectioned $(7 \mu \mathrm{m})$ to confirm which cell layers were dividing. Under safelight conditions the capsules/ sections were covered with a thin layer of K5 emulsion (Ilford Scientific, Moberley; diluted $1: 1$ with $\mathrm{ddH}_{2} \mathrm{O}$ ), the excess tipped off and the emulsion allowed to air dry. After 1 week at $5^{\circ} \mathrm{C}$, the capsules and sections were developed in Phenisol and fixed with Hypam (Sigma). Sections were then counterstained with Mayer's haematoxylin. The pattern of silver grains and counterstaining was assessed by standard light and fluorescence microscopy. The 

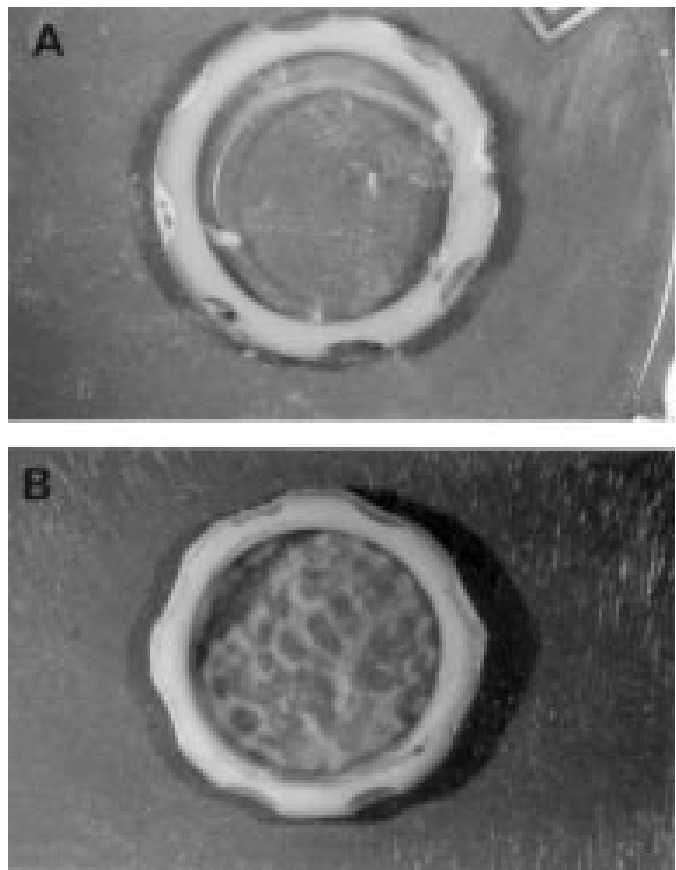

Figure 1 Bovine lens capsule with a silicone ring inserted. Immediately after insertion the capsule was clear $(A)$ but after 8 weeks in serum containing culture opacification was evident (B). Magnification $\times 2.5$.

proportion of dividing cells-that is, the number of nuclei which had incorporated label above background, was quantified at varying locations across the posterior capsule using the software package PC Image (Foster Findlay Associates, Newcastle upon Tyne).

\section{ANTIBODIES}

All antibodies were diluted in TRIS buffered saline (TBS) $\mathrm{pH} 7.6$ containing $0.2 \%$ normal goat serum. Details of the antibodies are as follows: a mouse monoclonal antibody to vimentin (clone V9), a marker for lens epithelial cells, was used at a dilution of $1 / 40$; a mouse anti-pan cytokeratin antibody, a marker for "non-lens"

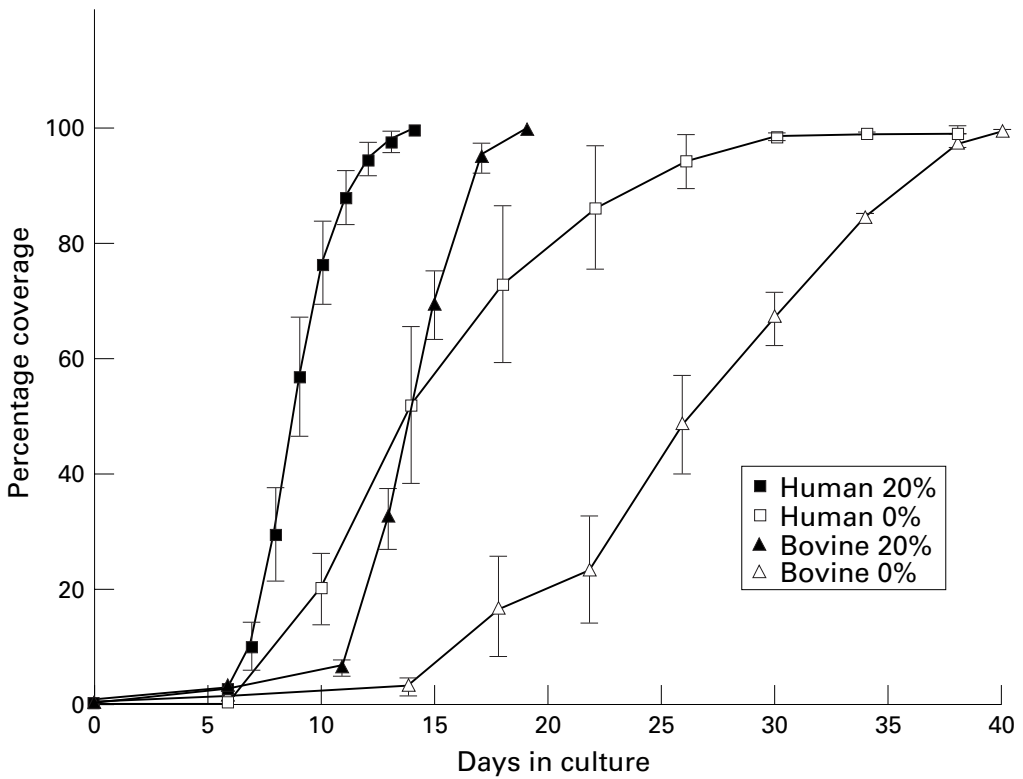

Figure 2 Graph showing the rate of coverage of bovine and human posterior capsules. The bovine data represent an average of results obtained for 18 capsules cultured in 20\% FCS and three capsules in 0\% FCS. The human data represent the average results obtained for 12 pairs of capsules, one of each pair in serum containing medium and the other in serum free medium. Vertical bars represent SEM. epithelial cells, was used at a dilution of $1 / 40$; a mouse monoclonal antibody to $\alpha$-smooth muscle actin ( $\alpha$-SMA), a marker for "fibroblast-like" cells, was used at a dilution of $1 / 400$ for whole capsules and 1/2000 for sections. Goat antimouse IgG conjugated to biotin was used as the secondary antibody at a dilution of $1 / 150$. All reagents used were from Sigma.

IMMUNOSTAINING OF SECTIONS

Wax sections ( $7 \mu \mathrm{m}$ thick) were dewaxed in xylene and then rehydrated in decreasing concentrations of alcohol. Sections were washed in TBS and the antigens exposed by digestion with $0.01 \%$ chymotrypsin in TBS $(\mathrm{w} / \mathrm{v})$ for 20 minutes at $37^{\circ} \mathrm{C}$. Sections were immersed in $3 \%$ hydrogen peroxide $(\mathrm{v} / \mathrm{v})$ for 5 minutes to remove the endogenous peroxidase activity. They were then washed in TBS and the non-specific background blocked by incubating for 20 minutes with normal goat serum diluted 1:5 with TBS. The serum was then tapped off and the primary antibody applied for 1 hour at room temperature. The samples were washed with TBS and incubated for 30 minutes with a goat anti-mouse biotinylated IgG conjugate. Slides were washed with TBS, incubated for 30 minutes with avidinbiotinylated horseradish peroxidase reaction complex (Dako, High Wycombe) and developed with DAB substrate solution. Positive staining was represented by a dark brown deposit. Sections were counterstained with haematoxylin to enhance visualisation. The sections were examined by standard light microscopy and photographed. All reagents used were from Sigma unless otherwise stated.

IMMUNOSTAINING OF WHOLE CAPSULES

For whole mount staining the silicone ring was removed from the capsule and a similar staining protocol used to that described above with the following exceptions: the samples were washed for longer between procedures, instead of treating with chymotrypsin cells were permeabilised with $0.2 \%$ Triton $\mathrm{X}-100$ (Sigma) in TBS for 30 minutes, the primary antibody was added for a minimum of 2 hours and capsules were incubated for 1 hour with the biotinylated IgG conjugate. The capsules were examined by standard light microscopy and photographed.

CONTROLS

Positive controls were bovine cornea for pan-cytokeratin and rat skin for $\alpha$-SMA and vimentin. Omission of either the primary or both the primary and the secondary antibodies on both the positive control tissues and bovine lens capsules were used as negative controls. Freshly isolated lens capsules with the remaining adherent epithelial cells were used as positive controls for actin and vimentin, and negative controls for cytokeratin and $\alpha$-SMA.

LOCALISATION OF FILAMENTOUS ACTIN

The ring was removed and the capsule washed with PBS for $3 \times 30$ minutes. Cells were then permeabilised with $0.2 \%$ Triton for $30 \mathrm{~min}$ utes, washed with PBS for $3 \times 30$ minutes and 

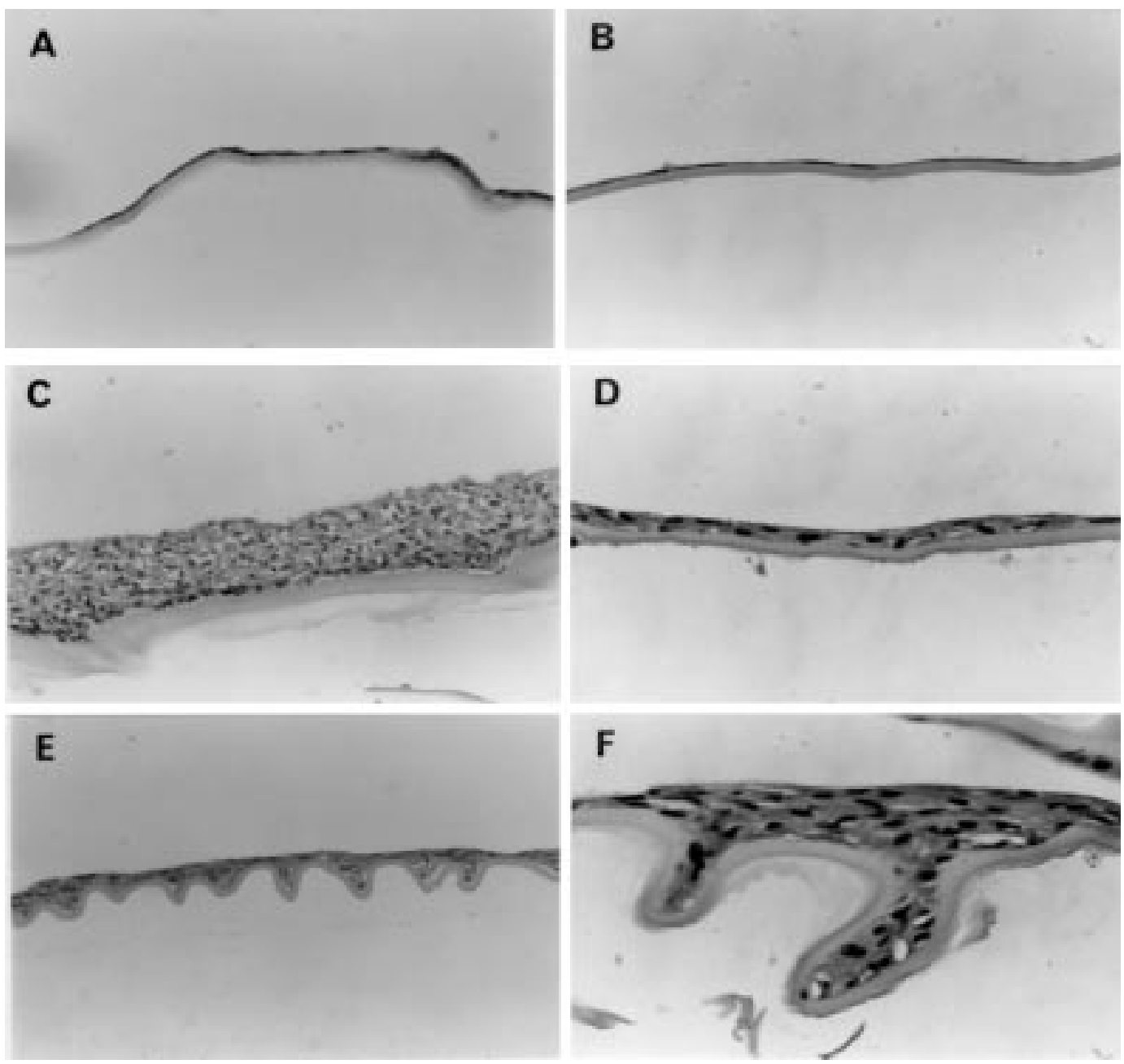

Figure 3 Histological sections of bovine $(A, C, E)$ and human $(B, D, F)$ posterior capsules at the different times of coverage; initial coverage as a monolaver $(A, B)$, formation of multilayers $(C, D)$, and wrinkling of the posterior capsule $(E, F)$. Capsules were maintained in serum containing medium. Sections were stained with haematoxylin and eosin. Original magnification $A, C$, and $E \times 143 ; B, D$, and $F \times 570$.

stained with a rhodamine-phalloidin conjugate $(0.83 \mu \mathrm{g} /$ capsule) (Sigma) for 1 hour. Capsules were washed with PBS for $3 \times 30$ minutes, mounted, and examined by standard fluorescence microscopy.

STATISTICAL ANALYSIS

The difference in coverage rates of the capsules was analysed by using the paired $t$ test. Comparison of the proliferative activity of the cells in the different regions of the posterior capsule was analysed using ANOVA.

\section{Results}

RATE OF COVERAGE OF HUMAN AND BOVINE CAPSULES

Both human and bovine capsules showed outgrowth of lens epithelial cells and eventual coverage of the posterior capsule. However, the timing of these events was dependent on both the species and the type of medium; in general, outgrowth and the rate of coverage was slower in the serum free than the serum containing medium.

Initial outgrowth of the human samples was observed from under the ring across the posterior capsule in all capsules cultured. This outgrowth occurred after a latent period of 5-8 days (mean $=6.1, \mathrm{n}=17$ ) and 5-12 days (mean $=7.7, \mathrm{n}=17$ ) for capsules cultured in the presence and absence of serum respectively. Although complete coverage was seen in all capsules cultured in serum containing medium, only $12 / 17$ reached complete coverage within 12 weeks in serum free medium. Capsules cultured in serum containing medium were covering at a significantly faster rate than those in serum free medium $(\mathrm{p}<0.05)$. The maximal rate of cell coverage was $20.06 \%$ and $7.75 \%$ coverage/day for serum containing and serum free medium respectively, and only appeared to slow once close to confluence. Capsules were completely covered within 5-11 days (mean 7.1 (SD 1.71)) and 12-69 days (mean 31.8 (20.32)) after initial outgrowth for serum containing and serum free medium respectively (Fig 2).

Initial outgrowth of the bovine capsules occurred in $25 / 28$ of capsules in serum containing medium but only $6 / 28$ capsules in serum free medium. This outgrowth was observed after a latent period of 5-15 days (mean 10.3) and 13-20 days (mean 17.2) in the presence and absence of serum respectively. Although complete coverage was seen in all capsules cultured in serum containing medium, only $3 / 6$ reached complete coverage within 12 weeks in serum free medium. Capsules cultured in serum containing medium were covering at a significantly faster rate 
than those in serum free medium $(\mathrm{p}<0.05)$. The maximal rate of cell coverage was greatest in serum containing medium (19.35\% coverage/day) and least in those capsules which exhibited coverage in the serum free medium (3/6) $(6.09 \%$ coverage/day). Capsules were completely covered within 4-10 days (mean 6.1) or 24-26 days (mean 25.0) of initial outgrowth for serum containing and serum free medium respectively (Fig 2 ).

MICROSCOPIC AND MACROSCOPIC APPEARANCE OF THE POSTERIOR CAPSULE

Although the majority of cells migrating across the posterior capsule had a regular cobblestone appearance there were often isolated "pioneer" cells at the leading edge. Wrinkles became visible in the posterior capsule of all samples at the later stages of cell coverage and increased in both length and number with time. Although there was some degree of variation in the amount of wrinkling this did not appear to be dependent on the concentration of serum used. The appearance of wrinkles correlated with an increase in the light scattering properties of the capsule. Gross examination of the preparations after several weeks in culture indicated that in all cases the posterior capsule had partially opacified and that this opacification was associated with the wrinkles (Fig 1B).

Although fibroblast-like cells were not seen on the posterior capsule of any of the human samples, sheets of these cells became visible within 40 days, and usually between $2-16$ days post-coverage in $17 / 25$ bovine samples cultured in serum containing medium. These cells were in a different focal plane and appeared to be migrating across the surface of the cells already covering the posterior capsule.

HISTOLOGY OF THE HUMAN AND BOVINE SAMPLES At the early stages of coverage cells formed a monolayer on the posterior capsule of both human and bovine samples (Fig 3A, B). However, as coverage continued cells at the leading edge were still found as a monolayer, but in the case of bovine capsules cells were sometimes two to three layers deep towards the equator. Once covered the cells formed multilayers across the posterior capsule (Fig 3C, D) reaching a maximum of five and 12 layers in human and bovine samples respectively. In both human and bovine samples multilayering was always greatest in serum containing medium. Cells were also found to multilayer on the posterior surface of the anterior capsule (up to six layers in bovine and two in human) but were often absent from the anterior surface of the anterior capsule. In cases where cells were observed on this surface they were only found as a monolayer and could be seen migrating around the capsulorhexis edge from the posterior surface of the anterior capsule. Cells never migrated onto the posterior surface of the posterior capsule. Wrinkles appeared to arise as a result of multilayers of cells contracting the posterior capsule (Fig 3E, F).
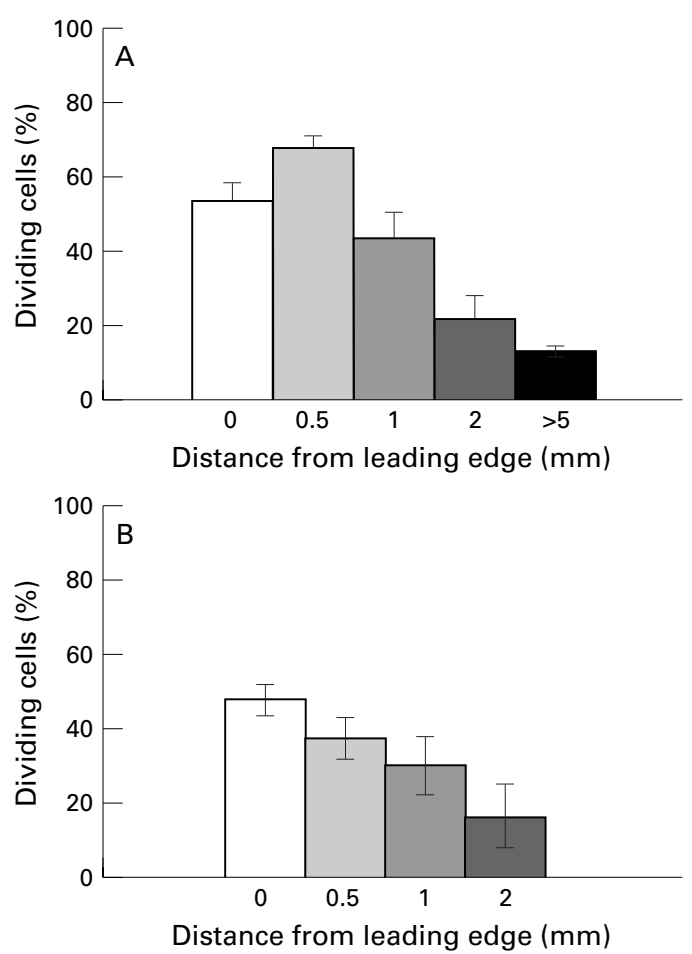

Figure 4 Proliferative activity of cells in the different regions of the bovine $(A)$ and human (B) posterior capsule. The data represent the average of results obtained from six bovine and six human capsules in serum containing medium at approximately 50\% coverage. Recordings were taken from the leading edge in three different regions of each capsule. Vertical bars represent SEM.

\section{THYMIDINE AUTORADIOGRAPHY}

The proportion of nuclei which had incorporated radioactive thymidine was greatest 0.5 $\mathrm{mm}$ behind the leading edge in the bovine samples and at the leading edge for the human capsules cultured in serum containing medium. Comparison of the different regions of the posterior capsule showed that the proliferative activity of the cells $0.5 \mathrm{~mm}$ from the leading edge of the bovine capsules was significantly greater than that 2 and $>5 \mathrm{~mm}$ away $(p<0.05)$ (Fig 4A). Similarly in human samples, the proliferative activity was greatest at the leading edge (Fig 4B), being significantly greater $(p<0.05)$ than at 1 and $2 \mathrm{~mm}$ away. The proportion of dividing cells on the pre-covered capsules cultured in serum free medium varied between 0.8 to 1.4 for human and 0.8 to $2.2 \%$ for bovine. Once the capsules were covered the cells continued to divide but the number of cells dividing at any one time was greatly reduced (less than $5 \%$ in serum containing medium). Once multilayered, labelled cells were normally found in the uppermost two layers of cells (that is, furthest away from the capsule).

LOCALISATION OF VIMENTIN, CYTOKERATIN, FILAMENTOUS ACTIN, AND $\alpha$-SMA

For both human and bovine tissue vimentin (Fig 5A) was immunolocalised to all cells while cytokeratin (Fig 5B) was absent, irrespective of the degree of capsular coverage or the number of cell layers present. The pattern of filamentous actin (F-actin) staining was similar for both the bovine and the human capsules. Isolated pioneer cells and those at the leading 

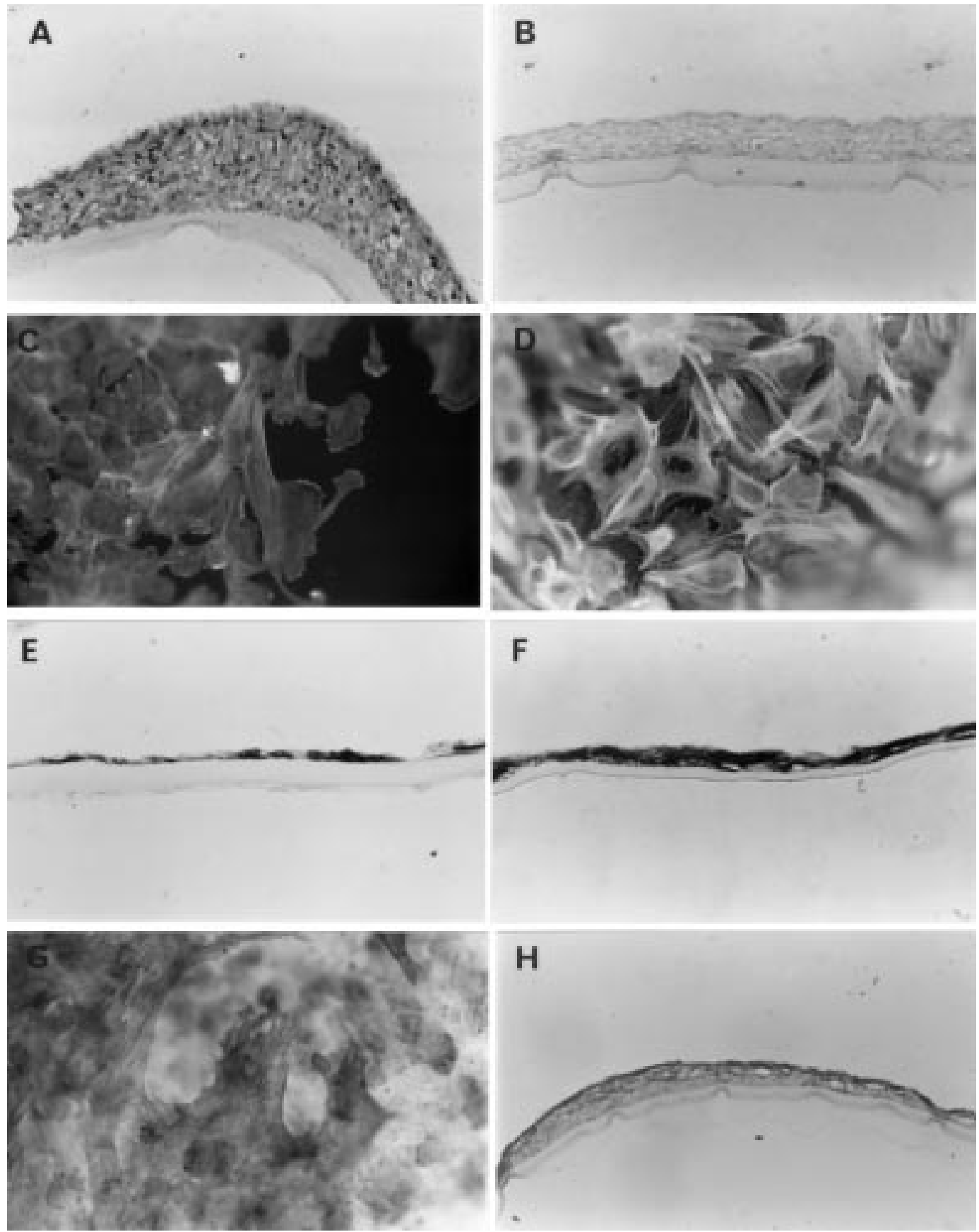

Figure 5 Localisation of vimentin (A), cytokeratin (B), F-actin (C,D), and $a-S M A(E-H)$ in cells on the bovine ( $A, B$, $C, G, H)$ and human $(D, E, F)$ posterior capsules at varying stages of coverage. All cells contained vimentin $(A)$ but cytokeratin was absent $(B)$. All cells stained for F-actin; microfilaments were polarised along the length of the cells at the leading edge $(C)$ and cells away from the leading edge had a perinuclear basket of F-actin (D). a-SMA was randomly distributed in the pre-covered capsules $(E)$ and found throughout the multilayers of the human post-covered capsules $(F)$. In the post-covered bovine capsules a-SMA was present in all fibroblast-like cells $(G)$ and throughout the multilayers although occasionally localised predominantly to the surface layers of the posterior capsule $(H)$. Capsules were maintained in serum containing medium. Original magnification of $A, B, D, H \times 143, C \times 160, E, F \times 570, G \times 64$.

edge had ruffled membranes. In some cases the filaments were oriented in the direction of migration whereas in other cells the actin filaments were radiating towards the cell membrane (Fig 5C). Cells behind the leading edge and those on the covered capsule had a perinuclear basket of F-actin (Fig 5D). Large amounts of $\mathrm{F}$-actin were aligned along the length of the wrinkles. $\alpha$-SMA was absent from residual lens epithelial cells on the freshly isolated capsules but was found in cells on all surfaces of the pre-covered human and bovine capsules. Cells at the leading edge normally contained $\alpha$-SMA, however, this contractile component was absent from some of the cells on the remainder of the posterior capsule (Fig $5 \mathrm{E})$. Once cell coverage was complete $\alpha$-SMA was normally found throughout the cell layers of both the human and bovine capsules, but interestingly not in all cells (Fig 5F). Immunostaining of post-covered bovine capsules indicated that all cells within the sheets of fibroblast-like cells contained $\alpha$-SMA (Fig 5G) and that this contractile component was particularly evident in the superficial layers of some regions of the posterior capsule (Fig $5 \mathrm{H}$ ). $\alpha$-SMA staining was present but variable in the anterior capsular cells; in some capsules all cells stained while in others only a proportion of the cells stained. 
CONTROLS

Cytokeratin was localised to corneal epithelial cells. $\alpha$-SMA was localised to smooth muscle cells around the blood vessels in the skin and vimentin to skin fibroblasts. There was no staining when either the primary or both the primary and the secondary antibodies were omitted from the staining protocol.

\section{Discussion}

We report on the characterisation of an in vitro model which exhibits many of the cellular characteristics of PCO. Initial studies in our laboratory assessed coverage of the posterior capsule using free floating specimens. This was relatively unsuccessful as the capsule rapidly contracted and it was impossible to observe and quantify cellular coverage of the posterior surface. To overcome this problem we elected to insert a silicone ring to maintain the circular contour of the capsular bag and prevent gross contraction. The insertion of a ring into the capsule has previously been used by Nagamoto et $a l^{19}$ and Hara et $a l^{2021}$ in experimental studies to reduce postoperative capsular bag shrinkage following ECCE. However, while they found that the rings reduced this shrinkage, their implantation also helped to maintain a transparent posterior capsule by acting as a barrier to the migrating cells. Therefore, in order to ensure that the ring used in our system did not inhibit the proliferation and migration of cells from the anterior capsule and equator onto the posterior capsule, ridges were cut into the sides of the ring in contact with the capsule. The slightly longer lag period in this study compared with that reported by Liu et $a l^{17}$ and Wormstone et al ${ }^{18}$ suggests that the rings may impede the initial outgrowth of lens epithelial cells. However, once outgrowth had occurred the rates of coverage were similar and epithelial cells were observed to readily migrate across the posterior capsule eventually forming multilayers in both, human and bovine specimens. The results of this study compare well with those described by Wormstone et $a l^{18}$ who similarly demonstrated the rate of human capsular coverage to be serum dependent. Given the interdonor variation it is unlikely that difference between the rate of cell coverage in the two studies, 25 days compared with 32 days in our model, is likely to be significant. However, the absence of complete coverage in $29 \%$ of samples cultured in serum free medium in our study contrasts with the $4 \%$ found by Wormstone et $a l^{18}$; this may reflect differences in technique and basal culture medium used. Despite the wide spread in donor age (50-93 years) in this study the absence of complete coverage of the posterior capsule did not correlate with donor age. It is tempting to speculate that the proliferative activity of the cells decreases as a function of environmental exposure (for example, diet and light) which is highly variable between individuals. Indeed, Wormstone and colleagues ${ }^{18}$ demonstrated a significant age dependent decrease in capsular coverage between donors of less than 40 years of age compared with those greater than 60 years of age. We were unable to confirm this observation since our specimens were all greater than 50 years of age.

The observation that cell coverage was significantly faster in serum containing medium is presumably due to endogenous serum growth factors such as bFGF and PDGF which are known to stimulate the proliferation and migration of lens epithelial cells. ${ }^{22}{ }^{23}$ It was apparent that serum dependency was much greater for bovine than human lens epithelial cells; only $15 \%$ of bovine capsules showed outgrowth in serum free conditions compared with $100 \%$ for human. In addition, once covered the degree of multilayering was much greater for bovine capsules compared to human. However, the coverage rate, proliferation profile and cytoskeletal organisation of the cells on the posterior capsule were similar between the two species. The similarity in coverage rate between human and bovine capsules was surprising in light of the observation that a faster coverage is expected of the young bovine lenses (approximately 1 year of age) compared with that of the old human lenses ( $>50$ years). Although the reason for this is unclear, it may relate to the fact that complete removal of the lens fibres was more difficult to accomplish in bovine lenses than human lenses; remaining lens fibres suppress the proliferative activity of lens cells. ${ }^{24}$ In light of these species differences it is recommended that care should be taken when selecting animal species to study a human condition.

Both human and bovine cells exhibited variation in spatial and temporal proliferative activity. Proliferation was greatest at or near the leading edge but decreased rapidly in the multilayers, being evident predominantly in the uppermost layers. This suggests that contact with the capsular substrate was an important factor in determining the rate of proliferation during the initial coverage of the capsule, and that cells in the deeper layers of the postcovered capsules were subject to density dependent inhibition of proliferation. ${ }^{92}$ An interesting observation was that the cells on the anterior surface of the anterior capsule, if present, were only found as a monolayer. The very low proliferative activity of cells in this region suggests that the majority of cells must have migrated round the edge of the capsulorhexis from the posterior to the anterior surface of the anterior capsule. Clinically, it is believed cells are often absent from this surface even in lenses which develop PCO (Knorr, personal communication). Globular shaped Elschnig's pearls, formed from the failed attempts of residual equatorial lens epithelial cells to differentiate into fibres, ${ }^{5}{ }^{10}$ were not observed during this study. It is possible that the capsules were not cultured for sufficient time for us to observe this type of cell behaviour or that all fibres were removed at the time of initial isolation.

As expected F-actin, a major cytoskeletal component, was found in lens epithelial cells both before and after capsulorhexis. However, the observation that $\alpha$-SMA was expressed in most human and bovine cells from the 
initiation of coverage was surprising. Its induction may have resulted from a number of stimuli-for example, surgical manipulation and change of environment (such as tissue culture medium). This work correlates with that of Nagamoto et al who have shown that $\alpha$-SMA is expressed in bovine, human, and rabbit epithelial explants both in the presence and absence of serum. ${ }^{26}$ Previous studies have also shown that $\alpha$-SMA can be readily induced in both bovine lens epithelial cells and rat epithelial cell explants following stimulation with TGF- $\beta .^{27}$ Although immunostaining for $\alpha$-SMA was apparent throughout the cell layers it was particularly evident at the leading edge and on occasions in the superficial layer of cells in a multilayer (especially those associated with the fibroblast-like cells seen in the bovine capsules). It is likely that this upregulation of $\alpha$-SMA may reflect areas of cell motility. Furthermore, the presence of $\alpha$-SMA, which is considered to be a marker for contractile cells, throughout the multilayers may explain the capsular wrinkling seen in our model. Since the expression of $\alpha$-SMA in the human samples was occurring before the change in cell shape associated with the appearance of fibroblastlike cells it suggests that the expression of this contractile component occurs independently of any morphological changes. Further studies at the biomolecular level are required to confirm the role of $\alpha$-SMA in PCO. The authors thank Dr Marcus Knorr and Professor David
McLeod for their helpful discussion during the preparation of McLeod for their helpful discussion during the preparation of this manuscript, and Gillian Williams, David Foreman, and project was supported by Research Into Ageing, London.

1 Courtney P. The national cataract surgery survey: I. Method and descriptive features. Eye 1992;6:487-92.

2 Stark WJ, Sommer A, Smith RE. Changing trends in intraocular lens implantation. Arch Ophthalmol 1989;107: $1441-4$.

3 Ohrloff C, Schalnus R, Rothe R, et al. Role of the posterio capsule in the aqueous-vitreous barrier in aphakic and pseudophakic eyes. F Cataract Refract Surg 1990;16:198201.

4 McDonnell PJ, Patel A, Green R. Comparison of intracapsular and extracapsular cataract surgery. Histopathologic study of eyes obtained postmortem. Ophthalmology 1985 92:1208-25.

5 Apple DJ, Solomon KD, Tetz MR, et al. Posterior capsule opacification. Surv Ophthalmol 1992;37:73-116.

6 Kappelhof JP, Vrensen GFJM. The pathology of aftercataract. Acta Ophthalmol 1992;70(suppl):13-24.
7 Green WR, McDonnell PJ. Opacification of the posterior capsule. Trans Ophthalmol Soc UK 1985;104:727-39.

8 McDonnell PJ, Stark WJ, Green WR. Posterior capsule opacification: a specular microscopic study. Ophthalmology 1984;91:853-6.

9 Sveinsson O. The ultrastructure of Elschnig's pearls in a pseudophakic eye. Acta Ophthalmol 1993;71:95-8.

10 Kappelhof JP, Vrensen GFJM, de Jong PTVM, et al. An ultrastructural study of Elschnig's pearls in the pseudophakic eye. Am f Ophthalmol 1986;101:58-69.

11 Olivero DK, Furcht LT. Type IV collagen, laminin, and fibronectin promote the adhesion and migration of rabbi lens epithelial cells in vitro. Invest Ophthalmol Vis Sci 1993; 34:2825-34.

12 Lovici FJ, Chamberlain CG, McAvoy JW. Differential effects of aqueous and vitreous on fiber differentiation and effects of aqueous and vitreous on fiber differentiation and plants. Invest Ophthalmol Vis Sci 1995;36:1459-69.

13 Odrich MG, Hall SJ, Worgul BV, et al. Posterior capsule opacification: experimental analyses. Ophthalmic Res 1985, 17:75-84.

14 McDonnell PJ, Rowen SL, Glaser BM, et al. Posterior capsule opacification. An in vitro model. Arch Ophthalmol 1985;103:1378-81.

15 Lundgren B, Jonsson E, Rolfsen W. Secondary cataract; an in vivo model for studies of secondary cataract in rabbits. Acta Ophthalmol 1992;205 (suppl):25-8.

16 Behar-Cohen FF, David T, D’Hermies F, et al. In vivo inhibition of lens regrowth by fibroblast growth factor 2-saporin. Invest Ophthalmol Vis Sci 1995;36:2434-48.

17 Liu CSC, Wormstone IM, Duncan G, et al. A study of human lens cell growth in vitro. A model for posterior capsule opacification. Invest Ophthalmol Vis Sci 1996;37:90614 .

18 Wormstone IM, Liu CSC, Rakic JM, et al. Human lens epithelial cell proliferation in a protein-free medium. Invest Ophthalmol Vis Sci 1997;38:396-404

19 Nagamoto T, Bissen-Miyajima H. A ring to support the capsular bag after continuous curvilinear capsulorhexis. $\mathscr{f}$ Cataract Refract Surg 1994;20:417-20.

20 Hara T, Hara T, Yamada Y. "Equator ring" for maintenance of the completely circular contour of the capsular bag of the completely circular contour of the capsular bag equator

21 Hara T, Hara T, Sakanishi K, et al. Efficacy of equator ring in an experimental rabbit study. Arch Ophthalmol 1995;113 1060-5.

22 Ibaraki N, Lin LR, Reddy VN. Effects of growth factors on proliferation and differentiation in human lens epithelial cells in early subculture. Invest Ophthalmol Vis Sci 1995;36: 2304-12.

23 Wunderlich K, Knorr M. Effect of platelet-derived growth factor PDGF on replication of cultivated bovine lens epithelial cells. Ophthalmologe 1994;91:98-102.

24 Rakic JM, Galand A, Vrensen G. Separation of fibres from the capsule enhances mitotic activity of human lens epithelium. Exp Eye Res 1997;64:67-72.

25 Alberts B, Bray D, Lewis J, et al. In: Molecular biology of the cell. 2nd ed. New York: Garland Publishing, 1989:727-90.

26 Nagamoto T, Eguchi G, Beebe DC. Control of $\alpha$-smooth muscle actin expression in cultured lens cells. Invest Ophthalmol Vis Sci 1997;38 (suppl):S43.

27 Hales AM, Schulz MW, Chamberlain CG, et al. TGF- $\beta 1$ induces lens cells to accumulate $\alpha$-smooth muscle actin, a marker for subcapsular cataracts. Curr Eye Res 1994;13: 885-90.

28 Kurosaka D, Kato K, Nagamoto T, et al. Growth factors influence contractility and $\alpha$-smooth muscle actin expression in bovine lens epithelial cells. Invest Ophthalmol Vis Sci 1995;36:1701-8. 